\title{
MANUFACTURING PROCESS OF CAR SPOILER PRODUCT USING CONTINUOUS RATTAN FIBER COMPOSITE MATERIALS
}

\author{
Agustinus Purna Irawan, Adianto and I Wayan Sukania \\ Department of Mechanical Engineering, Faculty of Engineering, \\ Universitas Tarumanagara, Jakarta, Indonesia
}

\begin{abstract}
This study aims to develop the process of manufacturing car spoiler products using continuous rattan fiber composite materials. Rattan fiber was chosen because of its good strength, abundant availability in Indonesia and inexpensive price. The study was conducted by testing the strength of a composite rattan fiber, simulation using computer software, comparing with pre-existing spoilers and making prototypes of spoilers. Based on the results of the study, the strength of continuous rattan fiber composite materials with polymer matrix is as follows: maximum tensile strength of 27 $M P a$, maximum compressive strength of $44 \mathrm{MPa}$, maximum flexural strength of 46 $M P a$, and maximum impact strength of $29 \mathrm{~kJ} / \mathrm{m}^{2}$. As a comparison, ABS plastic material used in many car spoilers has a maximum tensile strength of $35 \mathrm{MPa}$ a maximum compressive strength of $48 \mathrm{MPa}$, a maximum flexural strength of $56 \mathrm{MPa}$, and a maximum impact strength of $31 \mathrm{~kJ} / \mathrm{m}^{2}$. From the results of the simulation of loading using software carried out on the composite material of polymer rattan fibers, we obtain a compressive strength of $2000 \mathrm{~N}$ load of $51 \mathrm{MPa}$ with compressive strain of $0.00873 \mathrm{~mm} / \mathrm{mm}$. From the results of simulation loading using software carried out on ABS plastic material, we obtain a compressive strength for the $20110 \mathrm{~N}$ load of 48 $M P a$. The manufacturing process has produced a prototype of spoilers that are ready to use with good results. The results of this study will be a reference for the next development.
\end{abstract}

Keywords: Rattan fiber, composites, manufacturing, car spoiler.

Cite this Article: Agustinus Purna Irawan, Adianto and I Wayan Sukania, Manufacturing Process of Car Spoiler Product Using Continuous Rattan Fiber Composite Materials. International Journal of Mechanical Engineering and Technology 11(1), 2020, pp. 9-15.

https://iaeme.com/Home/issue/IJMET?Volume=11\&Issue=1

\section{INTRODUCTION}

The development of composite technology has now begun to experience a shift from synthetic fiber-reinforced composite materials to natural fiber-reinforced composite materials [1], [2]. This technological trend shift is based on the nature of the composite reinforced natural fibers 
that are more environmentally friendly, are widely available in nature, can be recycled and are relatively cheap [3]. This composite also has a high strength of density ratio so that the resulting component is lighter [4], [5]. The researchers used natural fiber composites as superior products according to their features. Although it does not completely replace synthetic fibers, the use of environmentally friendly natural fibers is a wise step to maintain environmental sustainability. Maya et al [6] conducted a review of natural fibers and bio composites. The result obtained is that natural fibers produce good interfacial interactions with resin as a matrix. Based on this research, a biomaterial consisted of ramie, bamboo and rattan fiber composites with a resin matrix is developed. Some natural fibers such as ramie fiber, bamboo, and rattan fibers have better mechanical characteristics compared to fiberglass, for instance, having higher elastic modulus, lower density, and lighter weight than fiberglass. However, the specific strength of those natural fibers approaches the specific strength value of fiberglass [6] - [8].

The potential of Indonesia's natural fiber is very abundant with various types of fibers that have good strength, but until now it has not been utilized optimally for the improvement of people's welfare. One of Indonesia's natural fiber potentials is rattan which has various types and qualities. Various types of good quality rattan thrive in various regions in Indonesia, especially on the islands of Kalimantan and Sumatera. Rattan fiber has good potential to be developed into bio composite materials that are environmentally friendly, inexpensive, strong, recyclable and renewable. Rattan fiber is produced in Indonesia's nature and is used as furniture [9] - [12].

Rattan fiber has the potential to be further developed to produce higher-value products such as automotive components. Until now, the development of rattan fiber-based products, especially in developing automotive products, has not been done much by researchers.

\section{METHOD}

\subsection{Material Preparation}

Rattan fiber composite material is produced by making rattan fiber swing from continuous rattan. The size of the rattan fiber as follows width: $2.5 \mathrm{~mm}$, thickness $1.5 \mathrm{~mm}$ and length 300 $\mathrm{mm}$. Rattan woven fiber is made in the direction of 0 degrees and 90 degrees, made not too tightly with the aim that the epoxy resin can get inside between the fibers so that it can bind the fibers well. The lamination process is carried out by pouring epoxy resin into the fiber, then a compressive process is carried out so that the resin can enter the fiber properly. This process is carried out in an epoxy rattan fiber composite mold [1], [2].

\subsection{Strength Testing}

Mechanical strength testing includes tensile strength ASTM D 3039/D3039M, compressive strength ASTM D 695, flexural strength ASTM D 730-03, impact test ISO 179:97, and morphological analysis using Scanning Electron Microscope (SEM). Comparative data from the strength of rattan fiber composite materials, obtained by testing the strength of ABS plastic materials and simulations using computer software [1], [2].

\subsection{Spoiler Prototype Manufacturing Process}

The making of car spoiler prototypes is done with a scale of 1:1 in the form of spoiler products for Innova and Fortuner cars. Prototyping was carried out in a workshop in collaboration with Small and Medium Enterprises that have been accustomed to making car spoilers from glass fiber material with a resin matrix. 


\section{RESULTS AND DISCUSSIONS}

\subsection{Mechanical Characteristics of Materials}

The research began by making mechanical strength test samples from continuous rattan fiber composite materials including tensile strength, compressive strength, flexural strength, and impact strength. The test results are compared with the strength of the spoiler products made from ABS plastic material. The data is also validated by simulations using computer software. The next step is to carry out morphological observations of continuous rattan fiber composite samples and ABS plastic. The data obtained were compared and analyzed, so that conclusions can be drawn on the potential of rattan fiber composites as car spoiler material.

The strength of spoiler products made from continuous rattan fiber composite materials with the polymer matrix and spoiler products made from ABS plastic material is shown in Table 1.

Table 1. The test result of mechanical characteristics of materials [1], [2]

\begin{tabular}{|l|l|c|c|}
\hline No. & Mechanical characteristics & $\begin{array}{c}\text { ABS plastic } \\
\text { material }\end{array}$ & $\begin{array}{c}\text { Continuous rattan fiber } \\
\text { composite material }\end{array}$ \\
\hline 1. & Tensile strength $(\mathrm{MPa})$ & 35 & 27 \\
\hline 2. & Compressive strength $(\mathrm{MPa})$ & 48 & 44 \\
\hline 3. & Flexural strength $(\mathrm{MPa})$ & 56 & 46 \\
\hline 4. & Impact strength $\left(\mathrm{kJ} / \mathrm{m}^{2}\right)$ & 31 & 29 \\
\hline
\end{tabular}

Based on the test results (Table 1), the biggest difference in tensile testing results is $22.8 \%$ and the smallest difference in impact testing is $4.3 \%$. The difference in overall average test results of $13.6 \%$ is still in a good value range. The biggest difference in tensile testing occurs due to the improper selection of test samples. The greatest tensile strength in the test is in the direction of the fiber. The greatest flexural strength of continuous fiber composites is obtained if the test is done perpendicular to the direction of the fiber. The selection of test samples is very important to produce good tensile and flexural strength. The difference in compressive strength is $8.8 \%$ and the difference in impact strength is $4.3 \%$. These results are very good and have the potential to be improved by a good composite manufacturing process. In this study, the focus of the strength to be achieved is the compressive strength of the spoiler material because it is related to the compressive force of the fastening bolts on the spoiler. Impact strength is also needed so that spoilers are not easily damaged in the event of a collision or vibration due to uneven road conditions. Continuous rattan fiber composites have good compressive and impact strength with a small difference in strength compared to spoilers made of ABS plastic [13], [14], [16].

From the loading simulation using software carried out on ABS plastic material, we obtain compressive strength for the $2000 \mathrm{~N}$ load of $44 \mathrm{MPa}$ with a compressive strain of 0.01851 $\mathrm{mm} / \mathrm{mm}$ (Figure 1). The difference in compressive strength of ABS plastic materials with rattan fiber composite materials and modeling results is $8.3 \%$ (Table 2). These results are very good and can be continued for the development of the spoiler product prototype manufacturing process using epoxy rattan fiber composite materials.

Table 2. The comparison of compressive strength of spoiler materials

\begin{tabular}{|l|c|c|c|}
\hline Mechanical characteristics & $\begin{array}{c}\text { ABS plastic } \\
\text { material }\end{array}$ & $\begin{array}{c}\text { Continuous rattan } \\
\text { fiber composite } \\
\text { material }\end{array}$ & $\begin{array}{c}\text { Loading } \\
\text { Simulation }\end{array}$ \\
\hline Compressive strength (MPa) & 48 & 44 & 44 \\
\hline
\end{tabular}



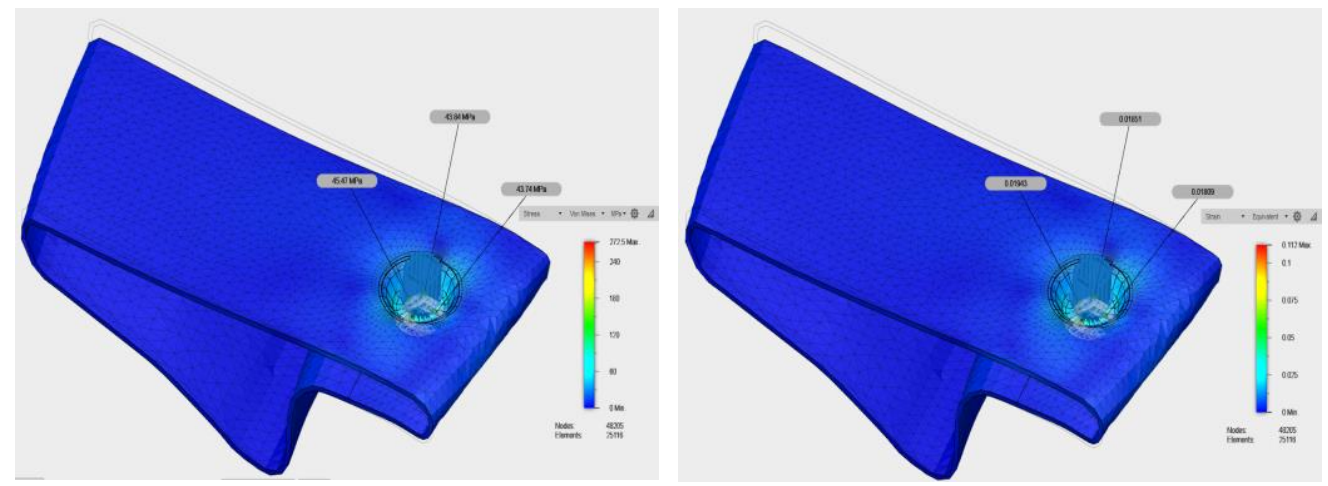

Figure 1 compressive loading simulation of spoiler material (2000 N) [1], [2]

If seen from the Scanning Electron Microscope (SEM) test results (Figure 2), it can be concluded that spoiler products with ABS plastic material only slightly experience voids. Thus it can be said that the manufacturing process carried out is good so that it produces good strength as well. In SEM testing of composite materials of epoxy rattan fiber, there are still many voids and the interface between the fiber and the matrix is still not good. This is what causes the power generated is still not optimal. Improvement of the manufacturing process of spoilers made from continuous rattan fiber composites can produce products with better strength [15], [16].

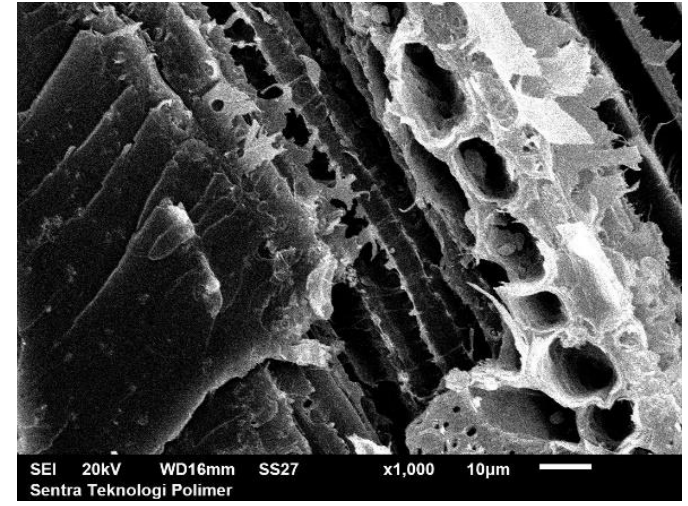

a. SEM of rattan fiber composite

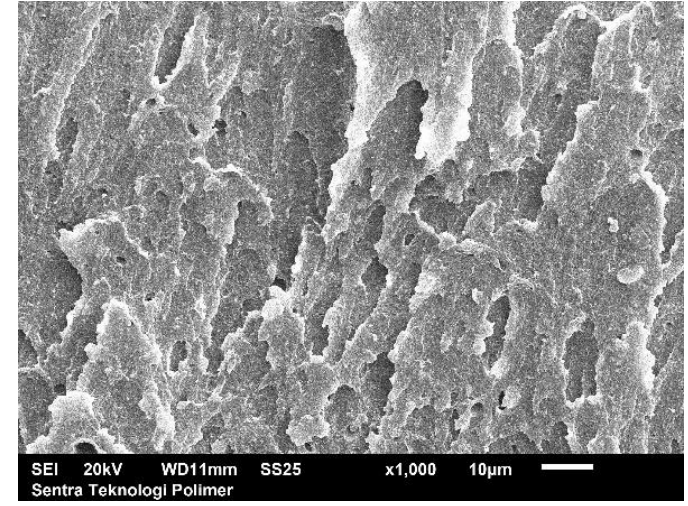

b. SEM of ABS plastic material

Figure 2 Morphology test using SEM 1000x [1], [2]

\subsection{Manufacturing Process of Spoiler Product}

The manufacturing process of car spoiler products based on continuous rattan fiber composites with a polymer matrix consisting of the following steps: making woven fiber rattan with fiber orientation $0^{\circ}$ and $90^{\circ}$, thickness $2 \pm 0.3 \mathrm{~mm}$ and width $4 \pm 0.2 \mathrm{~mm}$, size woven rattan fiber made with a length of $220 \mathrm{~cm}$ and width of $70 \mathrm{~cm}$, then soaked in $90 \%$ alcoholic liquid for 30 minutes and then dried. The next step is the manufacturing process by making a positive mold consisting of 2 parts, namely the top and bottom which both can be put together to form a spoiler product printed in it. If the positive print is ready, then a mirror grase is given on the inside of the upper print or the bottom mold so it is not sticky and the spoiler product can be easily removed from the mold. Mirror grase is the first layer of spoilers and continued with a continuous layer of rattan fiber, then laminated using a resin matrix and then tightly closed until it dries. The next step is to open the positive mold and remove the spoilers from the positive mold, finishing the spoilers so that they are ready to use (Figure 3 ) [1], [2], [17], [18]. 


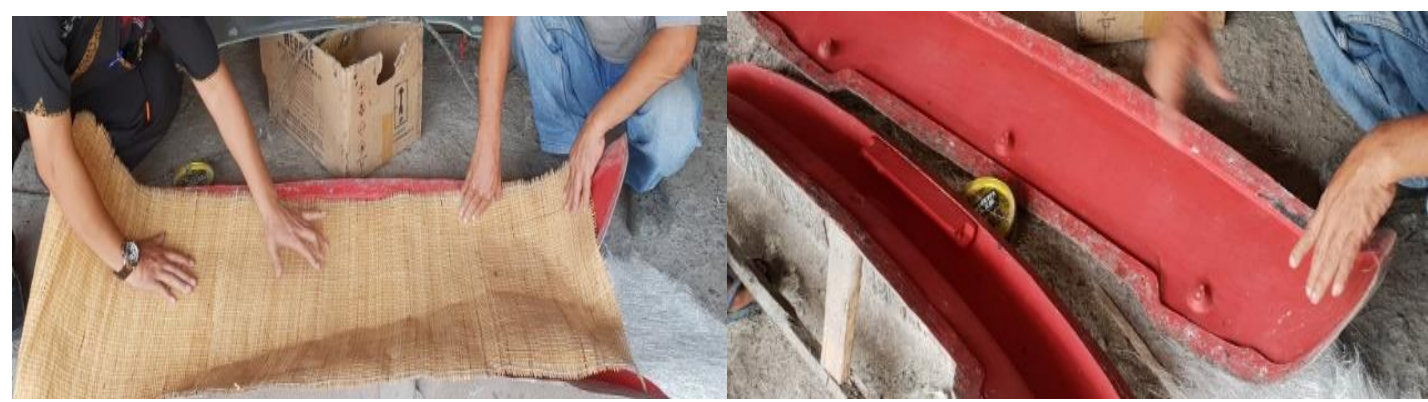

a. Preparation of rattan fibers and positive molds

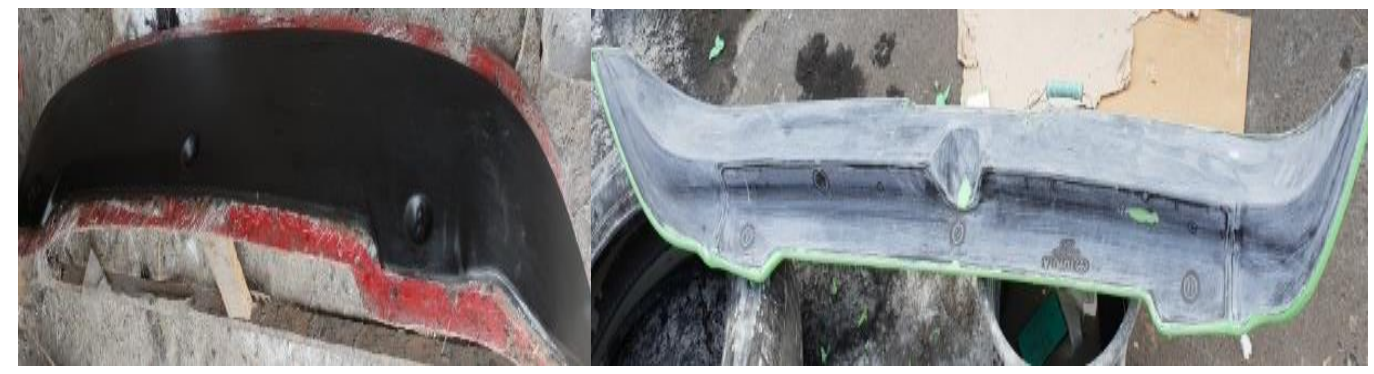

b. Manufacturing process of car spoiler

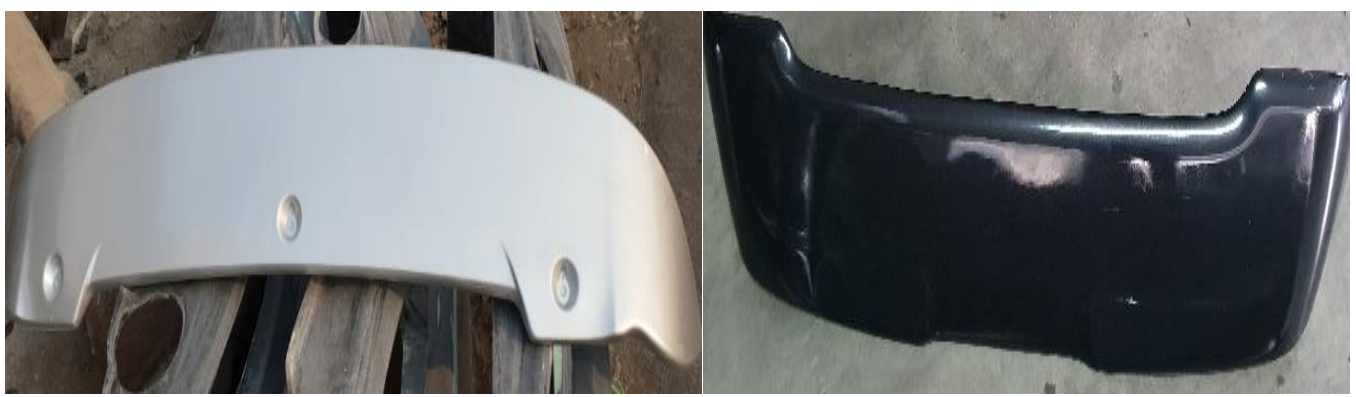

c. Product prototype of spoiler

Figure 3 Manufacturing process of car spoiler using rattan fiber composite

The process of developing a car spoiler product using rattan fiber composite materials has succeeded in making a prototype of a car spoiler product that is ready for use. Based on the research that has been done and the manufacturing process of car spoilers, it can be concluded that continuous rattan fiber in the form of weaving can be used as a raw material for making spoilers. However, from the prototype of the spoiler product that has been successfully developed, it is necessary to test and develop the best production process methods so that the product is strong and able to meet the aesthetic element, therefore they can be used by consumers as accessory products installed in cars and sold to the market (Figure 4) [1], [2], [19] - [21].
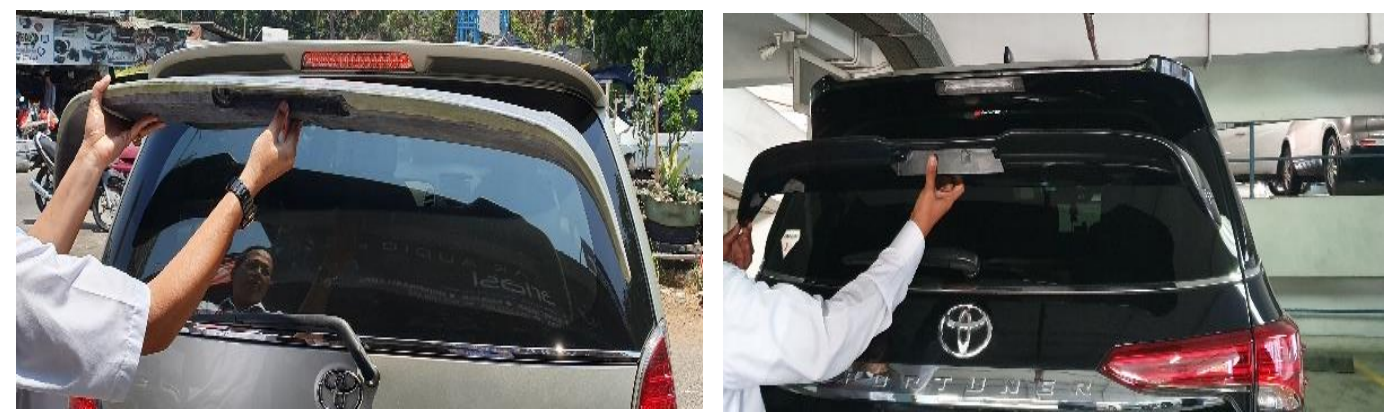

Figure 4 Product prototyping of car spoiler using rattan fiber composite 


\section{CONCLUSION}

Biomaterial research using rattan fibers with the epoxy matrix as an alternative material to make car spoilers has been successfully carried out well. The developed biomaterial is projected to replace synthetic fiber composite materials and ABS plastic. The tensile, compressive, flexural, and impact strength of epoxy rattan fiber composites produced is very good when compared to ABS plastic and simulation using computer software. The results of morphological analysis using SEM on epoxy rattan fiber composites showed a good bond between the fiber and the matrix. The voids that occur are seen only in small amounts. The results obtained are supported by a good spoiler prototype fabrication process, thereby reducing the number of voids. The making of the spoiler prototype shows that it has produced spoilers that are ready to be used. All of the results of this study will be a reference for further research in the development of automotive component products using natural fiber composites that are strong, inexpensive, recyclable, renewable and have abundant potential in Indonesia.

\section{REFERENCES}

[1] Irawan, A. P., Adianto, Sukania, I. W. Flexural strength of car spoiler materials made from rattan fiber composites. IOP Conference Series: Materials Science and Engineering, 420, 2018, pp. 1-5

[2] Irawan, A. P., Daywin, F. J., Fanando, and Agustino, T. Mechanical characteristics of rattan reinforced fiberglass and epoxy composites for shank prosthesis application. International Journal of Engineering and Technology, 8, 2016, pp. 1543-1550

[3] Irawan, A. P. Failure Mode Analysis of ramie fiber reinforced composite material. IOP Conference Series: Materials Science and Engineering, 420, 2018, pp. 1-8

[4] Mueller D. H., and Krobjilowski, A. New discovery in the properties of composites reinforced with natural fiber. Journal of Industrial Textiles, 33, 2003, pp. 111-130.

[5] Irawan, A. P., Soemardi, P. S., Widjajalaksmi K., and Reksoprodjo, A. H. S. Tensile and flexural strength of ramie fiber reinforced epoxy composites for socket prosthesis application. International Journal of Mechanical and Material Engineering, 6, 2011, pp. 46-50

[6] Jacob, M., Francis, B., Thomas, S., and Varughese, K. T. Dynamical mechanical analysis of sisal/oil palm hybrid fiber-reinforced natural rubber composites. Polymer Composites, 27, 2006, pp. 671-680.

[7] Irawan, A. P., Soemardi, P. S., Widjajalaksmi K., and Reksoprodjo, A. H. S. Gait analysis of the prosthesis prototype made from the natural fiber reinforced composite. Proceedings - Apchi-Ergofuture 2010, pp. 37-43

[8] Biagiotti, J., Puglia, D., Torre, L., and Kenny, J. M. A systematic investigation on the influence of the chemical treatment of natural fibers on the properties of their polymer matrix composites. Polymer Composites, 25, 2004, pp. 470-479.

[9] Irawan, A. P., Fediyanto, and Tandi, S. The design of bicycle for disable with ergonomic aspect consideration. Proceedings - Ergo Future 2006, pp. 337-341

[10] Irawan, A. P., Halim, A. and Kurniawan, H. Hybrid robot climbing system design. IOP Conference Series: Materials Science and Engineering, 237, 2017, pp. 1-8

[11] Irawan, A. P., Utama, D. W., Affandi, E., and Suteja, H. Product design of chairless chair based on local components to provide support for active workers. IOP Conference Series: Materials Science and Engineering, 508, 2019, pp. 1-6 
[12] Marizar, E. S., Irawan, A. P., and Beng, T. J. The knock down system of rattan furniture for global market. IOP Conference Series: Materials Science and Engineering, 508, 2019, pp. $1-5$

[13] Kaczmar, J. W., Pach, J., and Kozlowski, R. Use of natural fibres as fillers for polymer composites. International Polymer Science and Technology, 34, 2007, pp. T/45-T/50

[14] Ling-Ping, H., Yong, T., and Lu-Lin, W. Study on ramie, bambu, dan rotane fiber reinforced polypropylene composite (RF-PP) and its mechanical properties. Advanced Materials Research, 41, 2008, pp. 313-316

[15] Torres F. G., and Diaz, R. M. Morphological characterisation of natural fibre reinforced thermoplastics (NFRTP) processed by extrusion, compression and rotational molding. Polymers \& Polymer Composites, 12, 2004, pp. 705-718

[16] Rachchha, N. V., Ujeniyab, P. S. and Misrac, R. K. Mechanical characterisation of rattan fibre polyester composite. Procedia Materials Science, 6, 2014, pp. 1396 - 1404

[17] Khuong, T. L., Gang, Z., Farid, M., Yu, R., Sun, Z. Z., and Rizwan, M. Tensile strength and flexural strength testing of acrylonitrile butadiene styrene (ABS) materials for biomimetic robotic applications. Journal of Biomimetics, Biomaterials and Biomedical Engineering, 20, 2014, pp. 11-21

[18] Vácha, J., and Borůvka, M. Mechanical properties of acrylonitrile butadiene styrene thermoplastic polymer matrix with carbon nanotubes. Nanocon, 2015.

[19] Vishwakarma, S. K., Pandey, P. and Gupta, N. K. Characterization of ABS material: a review. Journal of Research in Mechanical Engineering, 3, 2017, pp. 13-16

[20] Kumar, M. V. S., Rao, B. A., and Mallaiah, G. Design, analysis and manufacturing of a car rear spoiler for drag reduction. International Advanced Research Journal in Science, Engineering and Technology, 4, 2017, pp 89-96

[21] Hamut, H. S., El-Emam, R. S., Aydin, M., and Dincer, I. Effects of rear spoilers on ground vehicle aerodynamic drag. International Journal of Numerical Methods for Heat \& Fluid Flow, 24, 2014, pp. 627-642 